\title{
The Effectiveness of 5E'S Learning Cycle Strategy in Developing Problem-Solving Skills for Learning Science Subject Among Third Grade Students
}

\author{
Haya Mohammad Aqeel \\ MA, Curricula and Teaching Department - Faculty of Educational Sciences, University of Jordan - Jordan \\ Ramzi Fathi Haroun, Prof. \\ Curricula and Teaching Department - Faculty of Educational Sciences, University of Jordan - Jordan
}

\begin{abstract}
The current study aimed at identifying the effectiveness of 5E'S learning cycle strategy in developing problemsolving skills for learning science subject among third grade students. In order to achieve the objectives of the current study, the researchers have developed a test to measure problem-solving skills in science among third grade students. The semi-experimental approach was adopted, as the study sample consisted of (38) students in Amman, with (20) students representing the experimental group, and (18) students representing the control group. The experimental group studied according to the 5E'S learning cycle strategy, and the control group studied according to the regular strategy. The results revealed that there were differences between the experimental group and the control group in the solving problems skills in science attributed to the teaching strategy in favor of the experimental group.
\end{abstract}

Keywords: 5E's Learning Cycle, Problem Solving Skills, Third grade

DOI: $10.7176 / \mathrm{JLPG} / 98-21$

Publication date:June 30th 2020

\section{Introduction and theoretical background}

Cognitive changes in a world characterized by speed prevailing in technology and information and problems are intertwined in all aspects of life, as politicians, society and educators face problems related to preparing a generation capable of resisting challenges. Hence the need to support learners to possess skills that accelerate their development and their success in solving their problems and granting them Lifelong learning.

The life of the individual is full of problems and challenges facing him, which are formed in his relationships with the learners, and other problems related to understanding feelings and emotions, some of which are related to possessing skills and their performance. Solving the problem requires scientific methods, as this requires skill and ability, so that the individual uses his knowledge to reach the optimal solution. The importance of the problemsolving skill of learners lies in inculcating the values of cooperation among them, assuming responsibilities, facing difficulties and promoting self-confidence, in addition to forming the characteristics of logical thinking (Abdul Hadi, 2004), and providing learners with problem-solving skills that are necessary in the twenty-first century (Blacky and Spence, 1990). Thus, educators and thinkers have direct students to acquire skills that enable them to control matters of their lives, such as critical thinking and problem solving (Jarwan, 1999) by placing students in problematic situations and events in order to enable them facing problems and work to solve them, where problem solving is a form of fact-finding, because the learner collects the information himself. Problem solving is the most important teaching objective around the world and the Arab countries (Al-Zuhairi, 2015).

The importance of problem-solving skills lies in the skills that make the learner practice an effective and organized role for his learning, and that it contributes to several areas in life, by supporting the learner in obtaining knowledge himself and creating an independent personality. Knowledge is multiple, so students must be trained in various methods of treating all types of knowledge. Thinking skills, including problem solving, are among the skills that an individual mustacquire to confront his problems, and then improve his life, by training him to analyze the problem so that he understands and clarifies it; the problem may be a question or attitude that requires an answer or a solution, and it may be a real or unreal, or a situation that raises confusion and tension for the learner. The importance of the problem-solving skill is that it helps the learner to make decisions in his life, so that he controls situations and circumstances (Nabhan, 2008).

Problem solving requires a number of steps and procedures that help the learner to reach a solution to the problem, as the steps varied from one researcher to another, in terms of their names and number. Al-Yamani (2009) believes that it includes feeling the problem, identifying and formulating it, collecting information related to the problem, developing hypotheses, choosing the most appropriate assumptions, verifying the validity of the hypotheses, reaching solution through the results, and generalizing the solution to similar problems. Abu Sammour (2015) indicates that it is defining the problem, linking the components of the problem, the multiplicity of alternatives and possible solutions, planning to find solutions, examining the choice and selecting it, then 
generalizing the results and applying the situation to similar situations. As for Nabhan (2008), he sees that the steps to solve problems are summarized by feeling, identifying and analyzing the problem, then collecting information about the problem, proposing solutions, and then studying the proposed solutions.

In the skill of defining the problem, the learner is assigned the task of finding solutions to the problems he faces, and in order to find these solutions he must admit that the problem exists. He also feels the difficulty beyond his abilities and skills, and this creates the incentive to find a solution. The learner does not only have to feel the problem and acknowledge its existence, but he has to understand it so that he can search for a solution, and this requires collecting information (Amwani, 2003). As for the skill of collecting information, this must be achieved through searching in books, references, sources, the Internet and any source that can be referred to in solving the problem. After the information gathering process, learners begin to organize the information to suit the study and arrange it (Tawalbeh, Al Sarayrah, Shamailah, and Sarayrah, 2010). It also means selecting the available resources for the solution, i.e. the learner chooses the information that is related to the problem, as he relies on references to choose information and classify and understand them, which is a basic plan to propose solutions (Otoum, 2004).

As for the skill of proposing solutions, it means finding alternatives, i.e. hypothetical solutions, and the solutions that students reach are related to the value of the information and experiences that students have, and their cognitive repository that they use in their access to solutions (Abu Sammour, 2015), and also is a complex process in which the learner uses all his logic and imagination; it is the most stressful problem solving process. Suggesting solutions is not a traditional process but rather critical, in which the learner accepts what is logical within his data (Zaitoun, 2014), and here the optimal solution is chosen through the comparison from among the solutions to reach the optimal one. It may be a logical solution, but it is difficult to realize (Al-Qaisi and AlDulaimi, 2009), and the learner uses in this skill several methods to address the solutions available to him in the previous skill in order to choose the best solution, so he compares the solutions and may use his knowledge to choose the best solution (Nashwani, 2003).

One of the most important goals that science education seeks to achieve is to develop problem-solving skills and thinking skills for learners, as teachers determine a goal that they seek to develop students 'abilities to confront problems. Teacher has specific roles to develop the problem-solving skills of learners, by using reinforcement methods and stimulating their motivation to encourage them to respond in these situations, and reformulating the academic content (the lesson) in the form of problems that challenge learners, and then makes the learner in a state of mental imbalance, and this is reflected in provoking their motivation to find solutions to the problem, as well as preparing a classy climate that is calm, warm and receptive and stimulates research and investigation, and provides students with a free expression of their thoughts, and their training in problem-solving skills, which is identifying and understanding the problem and collecting information and methods, as well as proposing solutions then choose the optimal and the most appropriate solution.

The teacher should use the methods of dialogue and debate, and motivate students to self-learning and discovery, and arrange the physical classroom environment in a way that allows students to be the focus of the educational learning process, and use tools and learning resources to support the learning process, and we should not lose sight of the importance of providing feedback to students that support them to reach solutions ,and how to direct them to additional learning resources, stimulate cooperative work and forming groups, giving each group an important or problem to solve it, and then initiate discussion between groups. The development of problemsolving skills depends on information and previous experience reference easily, so it is based on the information storage and retrieval methods (Salem 2013; Abdul-Aziz, 2007).

Teaching thinking is important, as it is a necessary educational process for every individual in our time, in order to adapt to changes and subject them to constructive criticism, and to go in the direction of change in order to develop and progress. Paying attention to the topic of teaching thinking increased through educational curricula, especially the science curriculum, as one of the purposes of the science curriculum is to teach thinking, not to stuff the minds of learners with information and knowledge without applying them and solving their problems (Zaytoun, 2009).

Teaching thinking and its skills in learning is an important need, because of the challenges and obstacles that persist in changing the learner's role in the learning process from a recipient to a producer of knowledge, and helping him to solve his problems (Jarwan, 1999). Therefore, the educational learning process must be improved and developed through teaching strategies that help to transforming regular teaching into active and effective teaching increases motivation and the learner is at the center of the educational process (Arafat, 2008).

Constructivism is one of the latest trends in education, with its educational applications playing an important and effective role with the participation of learners in order to build their concepts and knowledge, as the focus has shifted from external influences that reflect on the learner, such as the teacher, the school, and others, to internal influences that have an impact on the learner. This trend focuses on what happens inside the learner's mind when facing a situation, such as his previous knowledge, remembering and processing information, where Constructivism depends on everything that the learner has built from knowledge until it becomes meaningful learning. This reflects on his ability to solve his problems and confront them. Many strategies have been devised 
from this theory, which is one of the educational applications of Piaget's theory of cognitive development such as 5E'S learning cycle, conceptual maps, structural analytical model, and cooperative learning (Moses, 2015).

Learning Cycle, which is one of the strategies of constructivism, which was prepared by (Robert Karplus) and (Myron Atkin) emerged as a basis for organizing the science curriculum, which consisted of three stages: exploration, concept extraction and application, then the learning course was developed by the science curriculum team led by (Rodger Bybee) to (5E's), as it consists of five stages each stage begins with the letter (E). The (Engagement) stage is a stage in which the learner learns about the learning task, and links between previous and current experiences, by asking questions. As for the role of the teacher, it is determined by the learning task, and this stage is characterized by a loss of balance.

Exploration stage is the stage of providing learners with the necessary instructions and tools, to implement sensory activities until they are exposed to direct experiences, and the teacher's task is directed and guided. The Explanation stage is the stage in which learners explain their information in their own language, and the role of the teacher is to present and suggest explanatory learning experiences.

Elaboration stage is the stage to employ the information and interpretations that they reached in new experiences and situations, so as to expand their concepts and information, and the role of the teacher helps the learners to employ what they have learned in new situations. The Evaluation stage is the stage in which students assess their learning and self-understanding, and the role of the teacher is to verify the implementation of goals through tests and student achievement, and other assessment tools (Al-Hasanat, 2017; Zaitoun, 2007; Hosni, 2016).

(5E's) is distinguished from other teaching strategies and models with several advantages, as the learner is considered the center of the learning process, as he is active and positive and has a motivation towards learning and builds his knowledge by himself as an explorer and researcher. This strategy takes into account individual differences, because it is based on the knowledge that the learner builds through activities, and it also depends on cooperative work, so that experiences are exchanged through social negotiation among them. This strategy is characterized by achieving goals, as it reflects the nature of the survey, due to its reliance on direct experiences and investigation and the development of thinking and research skills. It also depends on the theoretical and philosophical literature of constructivist theory and Piaget's ideas, so learners become more comprehensible and contributes to retaining learning for the longest possible period of time, and this helps the teacher in effective planning and teaching. (Agha and Lulu, 2009; Musa, 2015).

\section{Literature review}

In this section, the researchers will review Arabic and foreign studies related to the current study and will comment on them. These studies will be presented in chronological order from oldest to the most recent as follows:

A study carried out by Ibrahim (2008) aimed to investigate the effect of using the modified 5 E'S learning cycle in teaching natural sciences in developing scientific thinking skills, and the ability to solve problems among students of the University College of Educational Sciences in Jordan. To achieve this objective, the study was applied to the study members, who were (60) male and female students of the second year level ( Specialization: A class teacher (from the UN College of Educational Sciences, divided into two classes who studied (unit movement, power and energy unit) from the normal sciences course; one of them represented the experimental group ,which consisted of (30) male and female students, who studied using the modified 5E'S learning cycle, while the other group was a "control group" which consisted of (30) male and female students, who studied using the traditional way. The results showed that there were statistically significant differences between the students of the experimental and control groups in both scientific thinking and the skills of problem solving, due to the cycle of teaching learning modified 5 E'S learning cycle and in favor of the experimental group.

Eliwa (2011) referred to a study that aimed to reveal the effect of three models of teaching methods (constructive for learning, creative problem solving and regular) in the ability to solve problems according to the cognitive style of students of the basic stage in physics. The study sample consisted of (135) students from the ninth grade, divided into three groups, and the researcher prepared a problem-solving test. The analysis showed that there were statistically significant differences $(\alpha=0.01)$ between the averages of female students in the three study groups on the problem-solving test attributed to the teaching method. The results showed that the average performance of female students who studied according to the two models was higher than the performance of female students who studied in the regular way, and the absence of a statistically significant effect at the level of significance $(\alpha=0.01)$, due to the interaction between the teaching method and the cognitive method in the problem-solving test.

Ibrahim's study (Ebrahim, 2012) was aimed at exploring the impact of the 5E'S Learning Course strategy and problem-solving on achievement of fifth-grade students in science. The researcher followed the quasiexperimental approach. The study sample consisted of all fifth grade students in Dezful.

The selection was made by two-stage cluster randomized approach. The results of the study indicated that there were statistically significant differences between the average achievement of students who received education through problem solving and the5E'S method), that is, students who studied the 5E'S course) scored 
higher than students who studied problem solving method. Also, there were differences between the average of achievement of the strong and weak students, who were taught by the 5E'S method and the students who were taught in a problem-solving way, and also there were no differences between the average achievement of the average students who were taught problem solving and the 5E'S method.

Al-Rashidi study (2013) aimed to find out the effect of the learning cycle strategy (5E'S) on the achievement and the development of critical thinking skills in physics for third-grade students in Saudi Arabia. The sample of the study consisted of (53) students who were purposively selected and divided into two divisions. One of the two divisions was experimental group and the other was the control group. To achieve the purpose of the study, the researcher worked on building a program using the (5E'S) learning cycle strategy and used the achievement test and the The California Critical Thinking Skills Test (CCTST). The results of the study revealed an effect of teaching using the (5E'S) learning cycle on achievement and the development of critical thinking.

The study carried out by (Susilowati \& Anam, 2017) indicated investigating the effectiveness of the 5E'S learning model (Engagement, Exploration, Elaboration, Expansion, Evaluation) in developing scientific thinking and problem solving in biology in Campec, Indonesia, and demonstrated the relationship between students 'scientific thinking and their ability to solve problems. The researchers used the experimental approach for one group. The sample of the study consisted of (60) students, and the results showed that there was a linear relationship between students 'scientific thinking and the ability to solve problems. The study confirmed that there was a need to the ability to think in problem solving, and that there was effectiveness for the learning model (5E'S) in developing the ability of scientific thinking and problem solving.

The study carried out by Qadri and Qawasmeh (2019) aimed to investigate the impact of using the computerized 5E'S strategy in acquiring scientific thinking skills in science for students of the fourth grade in Islamic Science College schools during the second semester (2015/2016), based on the semi-experimental design. In order to achieve this, the researchers prepared a measure of scientific thinking that has been applied after its validity and reliability have been verified on the study members. The sample of the study consisted of (48) male and female students divided into two groups, one is experimental group and the other is control group. The experimental group has studied using a computerized 5E'S learning cycle and the control group has using the regular 5E'S learning cycle. The results of the study showed that the achievement of the experimental group was higher than that of the control group, and the differences did not show a statistical significance at $(\alpha=0.05)$ attributed to the interaction between the teaching strategy and gender (male, female).

The foregoing showed the diversity of the variables covered by the studies, the diversity of samples, and the different places of application in foreign and Arab countries, and this indicates the effectiveness of the 5E'S learning cycle strategy. This research differs from the other studies in its focusing on third-grade students because most of the previous studies chose a sample of students in schools at higher levels, in addition to developing a scale for skills to solve science problems. The researcher benefited from it in identifying the concepts related to the study, and being guided by previous studies in building the tools necessary to achieve the purpose of the study, and identify many previous sources and references in writing the theoretical framework, choosing the appropriate research methodology, choosing the appropriate statistical methods, and comparing the results of the current study with the results of previous ones.

\section{The study problem and its questions}

The problem of the current study lies in teaching science through developing problem-solving skills. Ibrahim and Zaitoun (2005) believes that science education focuses on teaching methods that are concerned with cognitive aspects and this does not support the development of problem-solving skills, which are among the goals of science education. The study also showed that the learner receives the information and does not practice a method of solving problems and is inculcated knowledge step by step. The study carried out by (Al-Assali, 2014) also indicated that the strategies used in implementing the science curriculum have achieved negativity because the "female" teachers have focused on dialogue and textbook strategies, the lack of use of investigation and exploration strategies that develop students' higher skills in problem solving and critical and creative thinking.

Starting from the new role of the learner that he is not a "passive object" that relies on filling his mind with knowledge without applying it, and based on what the constructivism calls for regarding modern teaching strategies that develop thinking skills, and in light of the recommendations of some previous studies such as AlDhafiri (2010) and Ruili (2013), who stressed the necessity of conducting studies and research to get acquainted with the 5E'S learning cycle strategy and its effect on other variables, such as problem-solving, the current study came to identify the effectiveness of the 5E'S learning cycle strategy, which is one of the constructive strategies that may contribute to the development of skills to solve science problems.

This study attempts to answer the following question: 
What is the effectiveness of the 5E'S learning cycle strategy in developing the skills of solving science problems for third grade students?

The following hypothesis stems from the study question:

There is no statistically significant difference at the level of significance $(\alpha=0.05)$ between the mean scores of the experimental group and the control group on the scale of problem-solving skills, due to the teaching strategy (the 5E'S learning cycle strategy - the regular method).

\section{Objectives of the study}

This study seeks to identify the 5E'S learning cycle strategy, in addition to examining its effectiveness among third-graders, as this study seeks to reveal the effectiveness of the 5E'S learning cycle strategy in developing skills for solving science problems for third-graders.

\section{The importance of study}

The importance of the study lies in two main aspects, the theoretical and the practical aspects. The theoretical importance lies in that this study considers that trying teaching methods and models in the field of science education may lead to positive results in the educational process, where the 5E'S learning cycle strategy is consistent with the principles of structural theory that are centered in that the learner builds his knowledge by himself, by linking new experiences with previous experiences to form his knowledge.

The practical importance of the study lies in that its results may help provide teachers with how to employ the 5E's learning cycle strategy in science education, and develop students 'science problem-solving skills through this strategy, and improve their learning, as it provides a guide for the teacher to teach the unit chosen from the third-grade science textbook, designed based on the 5E'S learning cycle strategy as it provides a reference framework for how to teach in accordance with this strategy. It may contribute to directing science supervisors who are preparing curricula towards providing science curricula with modern strategies, such as the 5E'S learning cycle strategy, because of its benefits in developing aspects of thinking for the learner, and may contribute to providing a scale of science problem-solving skills for standard-setting.

It is expected that this study will benefit researchers in the field of teaching methods by opening new horizons for them to study for different age stages, and also provides them with a measure of the skills of science problem solving for third-graders, and a unit of study designed based on the 5E'S learning cycle strategy, and it also helps them in preparing the theoretical framework and study tools.

\section{Study limits and limitations}

The limitations of the study are:

Human limits: This study was applied to third grade students in Jordan.

Time limits: This study was applied in the first semester of (2018/2019)

Spatial limits: This study was applied to third-grade students in Al-Bayan School, the Department of Special Education in Marj Al-Hamam region.

Thematic limits: The study was limited to revealing the effectiveness of the 5E'S learning cycle strategy, by teaching the unit (the universe and life) from the science textbook for the third basic grade. The unit was built on the strategy in developing skills for solving science problems, and generalizing the results were determined in light of the study tools and their psychometric properties such as validity and reliability.

\section{Study terms and procedural definitions}

- The strategy: "It is a set of teaching procedures previously chosen by the teacher or the teaching designer, which is planned to be used during the course of the implementation of the lesson, in order to achieve the desired teaching goals as effectively as possible, and in light of the available capabilities." (Zaitoun, 2001, p. 281)

-The researchers define the strategy procedurally as: a set of steps that the researcher takes, in terms of planning, organizing and implementing them, through teaching a unit of science for the third grade of basic designed and based on the 5E'S learning cycle.

- The 5E's learning cycle: A developed form of the regular learning cycle that is used in teaching, where the teacher uses it with his students in the class in order for the student to build his knowledge by himself. The cycle stems from the structural theory in the design and organization of the study material, which consists of five consecutive stages, which are Engagement, Exploration, Elaboration, Expansion, Evaluation (Bybee, 1993)

- The researchers define the 5E'S learning cycle strategy procedurally as: a strategy for teaching a unit from the science textbook "the third basic grade", through the 5E'S learning cycle, as one of its goals is to develop the learner's ability to build his knowledge on his own. It works to attract the attention of students and give them the opportunity to implement activities that pave the way to developing the problem-solving skill, through the five stages of this strategy.

- Problem-solving skills: "The skills that are used to analyze and develop strategies aimed at solving a difficult 
question, complex situation, or issue at hand" (Al-Rafii, 2008, p. 15).

-The researchers define the 5E'S learning cycle strategy procedurally as: it is a set of steps that a student uses to solve a problem, and the student acquires it after studying a unit from the science textbook for the third grade based on the 5E'S learning cycle strategy. The student's acquisition of these skills will be measured by his score on the problem-solving skills scale prepared by the researchers.

\section{Method and procedures \\ Methodology}

The researcher have used the experimental approach (semi-experimental design) because it is suitable for study purposes related to the effectiveness of the 5E'S learning cycle strategy in developing skills for solving science problems for third-graders.

\section{Study population and sample}

The study individuals were chosen using the purposive sampling from one of the private schools in the capital, Amman, , because the researchers can follow up the study procedures correctly, because the private schools provide the tools necessary to implement the 5E'S learning cycle strategy that may need laboratories, tools, and smart tablets. Due to the cooperation of the school with the researchers in the application of the study, two divisions were chosen randomly, one of them was experimental group, the number of students was (20), and the other is control group, the number of students was (18), where the control group studied using the usual way, and the experimental group studied in the 5E'S learning cycle strategy. The two divisions were subjected to a pre-test of scale of skills for solving science problems", then teaching using the 5E'S learning cycle strategy for the experimental group, then the scale applied to the two groups using the post-test.

\section{Study tools}

\section{Strategy guide for the educational subject}

It is a guide that aims to inform the teacher to how to use the 5E'S learning cycle strategy in teaching the unit (universe and life). A strategy guide has been prepared to help the teacher implement the teaching plan for each unit lesson. The guide contains the introduction: The introduction includes introducing the guide, its goals and teaching method, the 5E'S learning cycle strategy, as it includes an introduction about it and its stages (Engagement, Exploration, Elaboration, Expansion, and Evaluation), examples of each stage, and the role of the learner and teacher in the strategy. The introduction includes the goals expected of students to achieve at the end of the unit, in addition to the time plan for teaching the unit, as it consisted of five lessons that require six classes over a period of three weeks. The introduction also included analyzing the content related to the "universe and life" unit, including concepts, facts, generalizations, values, directions, skills, steps for each lesson, learning resources and time needed, attaching a set of worksheets, adding a set of problems in the stages of the 5E'S learning cycle, the strategy's contribution to developing problem solving skills. The evidence was presented to a group of arbitrators specialized in the field of science in the methods of teaching science, curricula and teaching, and educational teachers from Queen Rania Academy, to express their views on the appropriateness of the educational material according to the 5E'S learning cycle strategy in developing problem solving skills in science, and the guide was modified according to the instruction of the jury.

\section{The scale of problem-solving skill for third grade students:}

It is a (pre and post test) essay questions, and multiple choice in the form of situations and problems consisting of (23) questions that fall under four skills (defining the problem, gathering information, proposing solutions, choosing the best solution) formulated with the aim of measuring effectiveness of the $5 \mathrm{E}$ 'S learning cycle strategy in developing problem-solving skills in science for third-grade students.

\section{Validity of problem-solving skill scale:}

The "test" scale was presented in its initial form to a number of specialists in the Curriculum and Instruction Department of the Faculty of Educational Sciences at the University of Jordan and educational supervisors at Queen Rania Academy for Teacher Training, to express their opinion regarding the test paragraphs and their clarity and relevance to the subject of study and their suitability for the age stage. Linguistic wording adjustments were made, and some inappropriate questions were deleted. Finally, the test consisted of four main areas (defining the problem, gathering information, proposing solutions, and optimal solution skill).

\section{The reliability of the problem-solving skill scale}

The stability of the test was verified by using the Cronbach's alpha coefficient, where the value of the stability coefficient using Cronbach's alpha for the defining the problem skill was (0.790), gathering information skill (0.837), proposing solutions skill $(0.917)$, the optimal solution skill $(0.800)$ and for the total score for problem 
solving skill scale $(0.780)$, which is acceptable values for the purposes of the current study.

\section{Study procedures}

To achieve the objectives of the study, the following steps were taken:

- Reviewing the previous studies related to the subject of the study, which were concerned with the effectiveness of the 5E'S learning cycle strategy in developing the skills of solving science problems among third-grade students. The researchers benefited from some studies such as (Ibrahim, 2008) and (Susilowati \& Anam, 2017) (Elewa, 2011) related to solving science problems.

- Verifying the validity and reliability of the study tools, which were composed of the scale of skills for solving science problems, and reviewing the theoretical literature in this field.

- Official approvals were obtained from the University of Jordan, in order to facilitate the task while applying the study tools.

- The study population individuals were identified in coordination with the private education schools that were concerned with the category (third grade primary stage students) and approved, in addition to coordination with the school administration for the participation of students in the study. To facilitate the process of implementing the strategy, the school was asked to apply the classes in one of its classrooms for a period of (6) lessons, so that the strategy was applied to the third basic students in the private schools in the experimental group and the application of the pre-test, and then the post test was applied at the end of the training on the strategy for each the scale of problem-solving in science to the control and experimental groups, as a step to reveal the effectiveness of the 5E'S learning cycle strategy in developing skills-solving skills in science subject for third grade students.

- After the practical procedures were implemented, the study tools were collected, corrected, and marks extracted, then data was entered into the computer as a prelude to extracting results using the SPSS software.

\section{Statistical analysis}

To answer the study questions, the following statistical methods were used:

1. Using the Cronbach's alpha test to verify the reliability of the study tools.

2. Means and standard deviations.

3. Two Way ANCOVA

4. Multiple Analysis of Co-Variance - MANCOVA.

\section{The results of the study and discussion}

\section{Results for the first hypothesis:}

There were no statistically significant differences at the level of significance $(5=0.05)$ between the mean scores of students of the experimental group and the control group, on the scale of problem-solving skills attributed to the method of teaching (the 5E'S learning cycle strategy - the regular method).

To examine the first hypothesis, the means and the standard deviations were calculated for the third grade students in the pre and post tests of the two experimental groups, which were subjected to the 5E'S learning cycle strategy in developing problem-solving skills in the science, and the control group that was subjected to the regular method, and the use of two-way ANCOVA for overall measurement, as well as using the MANCOVA to identify the significance of the differences between the two groups, for the sub-domains of the scale of problem-solving skills in the science subject, and the following shows the results:

\section{First: the total score}

Means and standard deviations were extracted to identify the average scores of the experimental group students, and the scores of the students of the control group in the post application of the problem-solving skills scale in science, as shown in Table (1):

Table (1): Means and standard deviations for problem-solving skills scale in science as a whole for both groups of studies on the pre and post scale

\begin{tabular}{|c|c|c|c|c|c|c|c|}
\hline \multirow{3}{*}{ Source } & \multirow{3}{*}{ Group } & \multicolumn{6}{|c|}{ Problem solving skills } \\
\cline { 3 - 9 } & & \multicolumn{4}{|c|}{ Pre-test } & \multicolumn{3}{|c|}{ post-test } \\
\cline { 3 - 9 } & & No. & Means & Standard deviation & No. & Means & Standard deviation \\
\hline \multirow{3}{*}{ Problem solving skills } & Control & 18 & 6.78 & 2.10 & 18 & 6.61 & 1.79 \\
\cline { 2 - 9 } & Experimental & 20 & 6.20 & 1.64 & 20 & 15.80 & 1.67 \\
\cline { 2 - 8 } & Total & 38 & 6.47 & 1.87 & 38 & 11.45 & 4.95 \\
\hline
\end{tabular}

The results shown in Table (1) show that the mean of the problem-solving skills scale in the science as a whole among a sample of students from the third grade of the control group the pre-in the pre-test is (6.78), with a standard deviation of (2.10), while the mean of the post-test of this group is (6.61), with a standard deviation of 
(1.79). The mean of the problem-solving skills scale in the science as a whole for a sample of students of the third grade of the experimental group on the pre-test is (6.20), with a standard deviation of (1.64), to become in the posttest (15.80) and a standard deviation of (1.67). In order to verify the significance of the apparent differences on the post-test, two Way ANCOVA results are shown in Table 2.

Table (2): Two Way ANCOVA results for the difference in the level of problem solving in science for the third grade students on the post test according to the (strategy) variable

\begin{tabular}{|c|c|c|c|c|c|c|}
\hline $\begin{array}{c}\text { Source of } \\
\text { variance }\end{array}$ & $\begin{array}{c}\text { Total of } \\
\text { squares }\end{array}$ & $\begin{array}{c}\text { Degrees of } \\
\text { freedom }\end{array}$ & $\begin{array}{c}\text { Average } \\
\text { squares }\end{array}$ & (F) & Significance & $\begin{array}{c}\text { Impact } \\
\boldsymbol{\eta} 2\end{array}$ \\
\hline Group & 812.75 & 1 & 812.75 & 302.58 & .000 & .896 \\
\hline Pre-tes tof skills & 13.46 & 1 & 13.46 & 5.01 & $.032^{*}$ & .125 \\
\hline Error & 94.01 & 35 & 2.68 & & & \\
\hline Corrected total & 907.39 & 37 & & & & \\
\hline
\end{tabular}

*:Significant at $(0.05)$ and below.

Table (2) shows that the value of (F) of the strategy variable is (302.58), which is significant at the level of $(0.05)$ and below. By reviewing the means, we notice that the mean of the level of problem-solving skills in science for the experimental group on the post-test was higher and that the mean of the control group individuals, which indicates a statistically significant difference at the level of significance (0.05) in the level of means of problemsolving skills in science for a sample of primary class students, due to the effect of the 5E'S learning cycle strategy in developing problem-solving skills in science for the third grade students.

The size of the effect of the strategy, according to the value of $\eta 2$, on problem-solving skills in science as a whole is $(0.896)$ which is a relatively large impact. Thus, the effectiveness of the strategy towards problem-solving skills in the subject of science is at a rate of $(89.6 \%)$ in general, meaning that $(89.6 \%)$ of the variation in the problem-solving skills in the science for third-grade students is due to the strategy variable, while the remainder of the variance ( $10.4 \%$ ) is unexplained, which is due to other uncontrolled factors.

In order to determine the value of the difference in the means of problem-solving skills in the science in the two groups (control and experimental) on the post-test, the adjusted means, resulting from isolating the effect of the marks of third-grade female students in the pre-test, were extracted on the scale of problem-solving skills in science in post-test, and the results were as shown in Table (3) below:

Table (3): Adjusted means for the third grade students on the scale of problem-solving skills in science according to the "group" variable

\begin{tabular}{|c|c|c|c|}
\hline Source & Group & Adjusted mean & Standard error \\
\hline \multirow{2}{*}{ Science problem solving skills } & Control & 6.51 & 0.39 \\
\hline & Experimental & 15.89 & 0.37 \\
\hline \multicolumn{2}{|c|}{ Total } & 11.20 & 0.27 \\
\hline
\end{tabular}

The results of the adjusted means for third-grade students on the scale of problem-solving skills in science in the experimental and control groups on the post-test, after isolating the effect of the pre-test,show that the differences were in favor of the third-grade students in the experimental group (the 5E'S learning cycle strategy in developing problem solving skills in science).

The problem-solving skills in the science for the scale as a whole for the experimental group have scored a mean of (15.89), while the control group scored (6.51), which indicates the effectiveness of the 5E'S learning cycle strategy in developing problem-solving skills in the science.

The following is the analysis for the sub-domains of the scale of problem-solving skills in science for the two groups of studies on the pre and post tests: 
Table (4): Means and Standard Deviations for a Problem-Solving Skills Scale for both Study Groups on Pre and Post tests

\begin{tabular}{|c|c|c|c|c|c|c|c|}
\hline \multirow{3}{*}{ Source } & \multirow{3}{*}{ Group } & \multicolumn{6}{|c|}{ Problem solving skills } \\
\hline & & \multicolumn{3}{|r|}{ Pre-test } & \multicolumn{3}{|r|}{ Pre-test } \\
\hline & & No. & Means & Standard deviation & No. & Means & Standard deviation \\
\hline \multirow{3}{*}{ Problem solving skills } & Control & 18 & 1.83 & 0.79 & 18 & 1.89 & 0.96 \\
\hline & Experimental & 20 & 1.95 & 0.89 & 20 & 3.90 & 0.79 \\
\hline & Total & 38 & 1.89 & 0.83 & 38 & 2.95 & 1.33 \\
\hline \multirow{3}{*}{ Information gathering } & Control & 18 & 1.61 & 0.61 & 18 & 1.72 & 1.07 \\
\hline & Experimental & 20 & 1.55 & 1.28 & 20 & 3.65 & 0.93 \\
\hline & Total & 38 & 1.58 & 1.00 & 38 & 2.74 & 1.39 \\
\hline \multirow{3}{*}{ proposing solutions } & Control & 18 & 1.67 & 1.08 & 18 & 1.39 & 0.78 \\
\hline & Experimental & 20 & 1.20 & 0.77 & 20 & 4.15 & 0.59 \\
\hline & Total & 38 & 1.42 & 0.95 & 38 & 2.84 & 1.55 \\
\hline \multirow{3}{*}{ the optimal solution skill } & Control & 18 & 1.67 & 1.03 & 18 & 1.61 & 1.09 \\
\hline & Experimental & 20 & 1.50 & 0.76 & 20 & 4.10 & 0.97 \\
\hline & Total & 38 & 1.58 & 0.89 & 38 & 2.92 & 1.62 \\
\hline
\end{tabular}

The results in Table 4 show that there are apparent differences between the means of the control group and the experimental group on the pre and post test. It is observed that the mean of the experimental group on the post test, which represents the level of problem-solving skills in its fields of (defining the problem, gathering information, proposing solutions, and optimal solution skill) among third-grade students, and with a view to verifying the fundamental apparent differences in post test MANCOVA analysis was used, the results of which are shown in Table 5 below:

Table (5): MANCOVA to identify the significance of the differences between the means of the members of the control group and the experimental group for the third grade students in the problem-solving scale in the post test

\begin{tabular}{|c|c|c|c|c|c|c|c|}
\hline Source & $\begin{array}{c}\text { Dependent } \\
\text { variables }\end{array}$ & $\begin{array}{c}\text { Total } \\
\text { squares }\end{array}$ & $\begin{array}{l}\begin{array}{l}\text { Degrees of } \\
\text { freedom }\end{array} \\
\end{array}$ & $\begin{array}{l}\text { Average } \\
\text { squares }\end{array}$ & $\mathbf{F}$ & Significance & $\begin{array}{c}\text { Impact } \\
\eta 2 \\
\end{array}$ \\
\hline \multirow{4}{*}{$\begin{array}{c}\text { Hoteling } \\
\text { Trace: } \mathbf{1 0 , 2 4} \\
\text { Significance } \mathbf{0 . 0 0 0}\end{array}$} & $\begin{array}{l}\text { Defining the } \\
\text { problem }\end{array}$ & 34.58 & 1 & 34.58 & 41.26 & $.000^{*}$ & .56 \\
\hline & $\begin{array}{l}\text { Gathering } \\
\text { information }\end{array}$ & 37.19 & 1 & 37.19 & 38.58 & $.000^{*}$ & .54 \\
\hline & $\begin{array}{l}\text { Proposing } \\
\text { solutions }\end{array}$ & 72.78 & 1 & 72.78 & 156.33 & $.000^{*}$ & .83 \\
\hline & Optimal solution & 49.11 & 1 & 49.11 & 57.69 & $.000 *$ & .64 \\
\hline \multirow{4}{*}{ Error } & $\begin{array}{l}\text { Defining the } \\
\text { problem }\end{array}$ & 26.82 & 32 & .83 & & & \\
\hline & $\begin{array}{l}\text { Gathering } \\
\text { information }\end{array}$ & 30.84 & 32 & .96 & & & \\
\hline & $\begin{array}{l}\text { Proposing } \\
\text { solutions }\end{array}$ & 14.89 & 32 & .46 & & & \\
\hline & Optimal solution & 27.23 & 32 & .85 & & & \\
\hline \multirow{4}{*}{ Corrected total } & $\begin{array}{c}\text { Defining the } \\
\text { problem }\end{array}$ & 65.89 & 37 & & & & \\
\hline & $\begin{array}{c}\text { Gathering } \\
\text { information }\end{array}$ & 71.36 & 37 & & & & \\
\hline & $\begin{array}{l}\text { Proposing } \\
\text { solutions }\end{array}$ & 89.05 & 37 & & & & \\
\hline & Optimal solution & 96.76 & 37 & & & & \\
\hline
\end{tabular}

*:Significant at $(0.05)$ and below.

Table (5) shows that the value of $(F)$ was $(41.26,38.58,156.33,57.69)$ and these are statistically significant values at the level of significance $(\alpha=0.05)$ between the control group and the experimental group on the posttest of the problem-solving scale represented in the fields (defining the problem, gathering information, proposing solutions, and optimal solution skill), and the value of Hotlling Trace is (10.24), which is a statistically significant 
value at the significance level (0.00), what confirms that there are significant differences between the control group and experimental group attributed to the strategy. When considering the means, it is clear that the differences were significant and in favor of the experimental group in the post test. This result is due to the effectiveness of the 5E'S learning cycle strategy in developing problem-solving skills for third-graders in private schools. The value of the impact size based on $\boldsymbol{\eta} \mathbf{2}$ on defining the problem (0.56), gathering information (0.54), proposing solutions (0.83), and optimal solution skill (0.643), all of which have a relatively large impact size.

To determine the value of the difference in the means of problem-solving skills in science in the two groups (control and experimental), on the post-test, the adjusted mean, resulting from isolating the effect of the scores of the third grade students on the pre-test, was extracted on the scale of problem-solving skills in science in the posttest .The results were as in Table (6):

Table (6): The adjusted mathematical averages for the third basic grade students on the scale of problemsolving skills in science subject according to the group variable

\begin{tabular}{|c|c|c|c|}
\hline \multirow{2}{*}{ Source } & Group & Adjusted mean & Standard error \\
& & & .22 \\
\hline $\begin{array}{c}\text { Defining the problem } \\
\text { Gathering information }\end{array}$ & Control & 1.90 & .20 \\
\cline { 2 - 4 } & Experimental & 3.88 & .23 \\
\hline Proposing solutions & Control & 1.65 & .22 \\
\cline { 2 - 4 } & Experimental & 3.71 & .16 \\
\hline $\begin{array}{c}\text { Defining the problem } \\
\text { Gathering information }\end{array}$ & Control & 1.32 & .15 \\
\cline { 2 - 4 } Proposing solutions & Experimental & 4.20 & .22 \\
\cline { 2 - 4 } & Control & 1.67 & .21 \\
\hline
\end{tabular}

The results of the adjusted means for the third grade students on the scale of problem-solving skills in science in the experimental groups and the control group on the post-test, and after isolating the effect of the pre-test, show that the differences were in favor of the third-grade students in the experimental group (the 5E'S learning cycle strategy in the development of problem-solving skills in science), as (the skill of defining the problem) scored a mean of (3.88), which is higher than the mean of the third grade students in the (regular) control group which scored (1.90), and the skill of Gathering information for the experimental group which scored (3.71), while the control group scored a mean of (1.65), and the skill area for suggesting solutions for the experimental group obtained an average score (4.20), while the control group obtained an average score (1.32), and the skill of the optimal solution for the experimental group scored a mean of (4.04), while the control group scored (1.67). Thus, we reject the null hypothesis in favor of the alternative hypothesis, and this indicates the effectiveness of the 5E'S learning cycle strategy in developing problem-solving skills in the science among third-graders.

The researcher attributes the experimental group's superiority over the control group to the diversity of learning activities that the 5E'S learning cycle strategy contained, as it made the learners launch solutions and ideas for the problems they face; which is the focus of the educational process, as the strategy has played an important role in making the student able to solve problems. In the Engagement stage, we put the student in a confusing situation that requires him to identify the problem and its causes, while in the exploration stage he starts collecting information about the subject of the problem or the confusing situation, and then puts the proposed solutions with his colleagues within the group, and he tests and verifies them. This is consistent with the study carried out by Eliwa (2011) in that when students solve a problem through the procedures followed by the strategy, they try to understand the problem and put the proposed solutions and then determine the appropriate method to choose the optimal solution.

As for the elaboration stage, the student submits proposals for solutions to his colleagues. In the expansion phase, the learner's awareness increases by linking what he has learned with daily situations, and the appropriateness of the proposed solutions for their application in reality, and here the skill of choosing the optimal solution and the ability to apply it in life develops; that is, the function of knowledge, and we do not lose sight of the evaluation stage in each stage, by asking questions that contribute to developing problem-solving skills, and placing the student in new situations and problems, to demonstrate his ability to solve problems; students themselves practiced problem-solving skills. This is confirmed by a study carried out by (Ibrahim, 2008) and the study showed that individuals have the ability to generate ideas and practice smart ways to solve problems, and that the strategy helped them to increase their ability to search in their knowledge stock and link their previous with the new experiences and this contributed to the development of their ability to solve problems.

The 5E'S learning cycle strategy is far from indoctrination as it is based on the student, and as mentioned by (Moussa, 2015) that The 5E'S learning cycle strategy provides time for research and investigation to discover concepts, and provides the appropriate environment that gives the student the opportunity to face problems that challenge his thinking, and this result can be explained as that 5E'S learning cycle strategy has worked to break 
the routine in education, so that it meets the needs of learners.

The 5E'S learning cycle strategy is one of the strategies of constructivism theory, which depends on several foundations as mentioned by Qarni (2013) that it makes learners in real problems, and it motivates them to research and investigate, and is based on dialogue and discussion, and this is provided by the 5E'S learning cycle strategy as it puts them in problems from their reality and forming groups for dialogue and discussion among themselves to propose appropriate solutions, and thus works to form a constructive learner as mentioned by (Al-Yamani, 2009; Philps, 1995) as being the creative learner who discovers everything that is new so that he discusses and builds his assumptions and his understanding and makes testable forecasts .

This is provided by the 5E'S learning cycle strategy, where it develops higher-order thinking skills and the ability to define and explain the problem and develop proposed solutions based on its assumptions, and reaches an optimal solution based on verifiable predictions. This is supported by the study carried out by (Susilowati \& Anam, 2017)) that this model aims to train students to develop their ability to think and solve problems, and to develop their ability to make decisions and higher thinking skills that support problem solving and these skills are important in learning science that links more than one concept with each other.

\section{Recommendations}

In light of the results of the study, the researchers recommend the following:

1- Conducting studies for grades other than the third basic grade and for other subjects.

2- Holding courses for teachers and educational supervisors on constructive teaching method using the five-year learning course.

3- Instructing educators about formulating curricula that contain activities that develop higher thinking skills, including research, exploration, evaluation, and use of the learning course and its applications in preparing materials.

\section{References}

Abdul Hadi, Nabil (2004). Contemporary Educational Models, $2^{\text {nd }}$ Edition, Amman: Dar Wael.

Abdulaziz, Saeed (2007). Teaching thinking and its skills, (1 ${ }^{\text {st }}$ edition $)$, Amman: Dar Al Thaqafa for Publishing and Distribution.

Abu Sammour, Muhammad (2015). Effective Classroom Teaching Skills and Curriculum Control ( $1^{\text {st }}$ edition), Amman:Dar Dijla for Publishing and Distribution.

Agha, Ihsan and Lulu, Fathiya (2009). Teaching science in general education, ( $2^{\text {nd }}$ edition), Gaza: Afaq Library.

Al-Assali, Anhar (2014). The reality of the implementation of the educational learning process (student, teacher) for the science curriculum for the fourth grade of basic education in the schools of Nablus / Palestine, unpublished doctoral thesis, International Islamic Science University, Jordan.

Al-Atoum, Adnan (2004). Cognitive Psychology (Between Theory and Practice), Amman: Dar Al Masirah for Publishing and Distribution.

Al-Dhafiri, Bushra (2010). The Impact of a Modified(5E'S) Learning Course Strategy on Achievement and Creative Thinking among Fifth Grade Students in Science in the State of Kuwait, Unpublished Master Thesis, Middle East University, Amman, Jordan.

Al-Qaisi, Abdul Ghaffar and Al-Dulaimi, Sawsan (2009). Motor perception among high-achieving and late students in middle schools. Journal of Educational and Psychological Research, (22), 21-66.

Al-Rafii, Yahya Abdullah (2008). The effect of some principles of innovative solutions to problems according to the (TRIZ) theory on developing innovative thinking among a sample of the gifted in the first secondary class, unpublished Ph.D thesis, Umm Al-Qura University, Makkah Al-Mukarramah, Saudi Arabia.

Al-Rashidi, Ali (2013). The effect of using the (5 E's learning cycle strategy) on achievement and developing critical thinking skills in physics for third year secondary students in the Kingdom of Saudi Arabia, unpublished master's thesis, Mu'tah University, Karak, Jordan.

Al-Ruwaily, Badr Hussein (2013). The effect of using 5E'S learning cycle strategy model on the achievement and development of critical thinking among fifth-grade primary students in science subject in Qurayyat governorate, unpublished master thesis, Mu'tah University, Karak, Jordan.

Al-Yamani, Abdul Karim (2009). Learning and Teaching Strategies, ( $1^{\text {st }}$ edition $)$, Amman: Zamzam House for Publishing and Distribution.

Al-Zuhairi, Haider (2015). Contemporary Curricula and Teaching Methods. I (1), Amman: Dar Al Yazouri for Publishing and Distribution.

Arafat, Najah (2008). The effectiveness of 5E'S learning cycle strategy in biology teaching on the development of achievement, the generation of information, its evaluation, and the trend towards biology among high school students. Journal of the Faculty of Education, Fayoum, (8), 194-288.

Blakey, E., \& Spence, S. (1990). Developing Metacognition. ERIC Digest.

Bybee.R.(1993).Instruction of Model for Science Education.In Developing Biological Literacy. Coloreds 
Springs ,Co: Biological Curriculm Studies.

Ebrahimi, S. (2012).Comparing the Effect of 5 E and Problem Solving Teaching Methods on the Students' Educational Progress in the Experimental Sciences Course. Journal of Basic and Applied Scientific Research, 2(2), 1091-1100.

Eliwa, Raed (2011). The effect of models of teaching methods on the ability to solve problems according to the cognitive style of students of the upper basic stage in Jordan. Educational Journal, 25 (99), 337-376.

Hasanat, Khawla (2017). The effect of using 5E'S learning cycle and conceptual maps strategies on acquiring sixth-grade students for critical thinking skills in the light of their self-efficacy. Journal of the Islamic University for Educational and Psychological Studies, Research and Graduate Studies Affairs at the Islamic University of Gaza, 25 (2), 419-445.

Hosni, Ghada (2016). Constructivism theory is a contemporary approach to improving the learning environment, I (1), Cairo: Books World for Publishing and Distribution.

Ibrahim, Bassam (2008). The effect of teaching natural sciences using the learning cycle (5E'S) on developing basic cognitive economy skills among students of the University College of Educational Sciences in Jordan. An-Najah University Journal for Research (Humanities), 22 (4), 1331-1351.

Ibrahim, Lina and Zaitoun, Ayesh (2005). The reality of science education in the first three grades in Jordan and ways to develop it in the light of contemporary trends in practical education, unpublished P.hD thesis, Amman Arab University, Jordan.

Jarwan, Fathi (1999). Thinking Education Concepts and Applications, Al Ain Al-Emaratiya: University Book House.

Musa, Raja'a (2015). The effect of using both 5E'S learning cycle strategy and the similarities on developing some habits of mind among seventh graders. Journal of Scientific Research in Education, 2 (16), 315-356.

Nabhan, Yahya (2008). Brainstorming and Problem Solving, Amman: Al-Yazouri Scientific House for Publishing and Distribution.

Nashwani, Abdul Majeed (2003). Educational Psychology, Amman: Dar Al-Furqan for Publishing and Distribution.

Phillips, D. C. (1995). The good, the bad, and the ugly: The many faces of constructivism. Educational researcher, 24(7), 5-12.

Qarni, Zubaida (2013). Student-centered active learning strategies and their applications in learning situations. I (1), Cairo: The Modern Library for Publishing and Distribution.

Qawasimah, Rasha and Al-Qadri, Suleiman (2019). The effect of using 5E'S learning cycle strategy in acquiring scientific thinking skills in science subject for fourth-grade students. Educational Science Studies, 46 (2), 302-322.

Salem, Hamada (2013). A proposed program based on brain-based learning in developing problem-solving skills for low academic achievement students in primary school. Journal of Scientific Research in Education, (14), Part 1, 685-711.

Susilowati, S. M. E., \&Anam, K. (2017). Improving Students' Scientific Reasoning and Problem-Solving Skills by The 5E Learning Model. Biosaintifika: Journal of Biology \& Biology Education, 9(3), 506 - 512.

Taner, PervinOya(2010). Implementation of Contructive Life Sciences Curriculm: Acase Study.Athesis Submitted for Doctoral Degree,Middle East Teaching University, Turkey.

Tawalbeh, Hadi and Al Sarayrah, Basem and Shamayleh, Nisreen and Al Sarayrah, Khaled (2010). Teaching methods, i (1), Amman: Dar Al Masirah for Publishing and Distribution.

Zaitoun, Ayesh (2007). Structural theory and science teaching strategies. I (1), Amman: Dar Al-Shorouk for Publishing and Distribution.

Zaitoun, Ayesh (2009). Science teaching methods. Amman: Dar Al-Shorouk.

Zaitoun, Ayesh (2014). Methods of Teaching Science, I (7), Amman: Dar Al-Shorouk for Publishing and Distribution.

Zaitoun, Hassan (2001). Teaching design, systemic vision. I (2), Cairo: The World of the Book. 